\title{
A latent profile approach for the study of internet gaming disorder, social media addiction, and psychopathology in a normative sample of adolescents
}

This article was published in the following Dove Press journal:

Psychology Research and Behavior Management

\section{Luca Cerniglia ${ }^{1,2}$ \\ Mark D Griffiths ${ }^{2,3}$ \\ Silvia Cimino 2,4 \\ Valeria De Palo ${ }^{2,5}$ \\ Lucia Monacis ${ }^{2,5}$ \\ Maria Sinatra ${ }^{2,6}$ \\ Renata Tambelli ${ }^{4}$}

'Department of Psychology, International Telematic University Uninettuno, Rome, Italy; ${ }^{2}$ Centre for Advanced Studies on Cyberpsychology and Ethics (ASPEN), University of Bari, Bari, Italy;

${ }^{3}$ International Gaming Research Unit, Division of Psychology, Nottingham Trent University, Nottingham, UK;

${ }^{4}$ Department of Dynamic and Clinical Psychology, University of Rome "la Sapienza", Rome, Italy; ${ }^{5}$ Department of Humanities, University of Foggia, Foggia, Italy; ${ }^{6}$ Department of Educational Sciences, Psychology, Communication, University of Bari Aldo Moro, Bari, Italy
Correspondence: Luca Cerniglia Department of Psychology, International Telematic University Uninettuno, Corso Vittorio Emanuele II, 39, Rome, Italy Email I.cerniglia@uninettunouniversity.net
Background: For a small minority of individuals, the overuse of digital technologies has been associated with negative factors, including psychological distress and psychopathological symptoms. Two technology-based addictions - internet gaming disorder (IGD) and social media addiction (SMA) - have been found to be related to comorbid disorders and impulsivity especially in adolescents and emerging adults' populations, but results in this field are inconclusive

Purpose: Using the latent profile analysis (LPA), this study identified different profiles of adolescents characterized by unique patterns of psychopathological risks, and similar levels of impulsivity, IGD, and SMA.

Participants and methods: A total of 643 participants ( 312 males; $M_{\text {age }}=16.02$ years) were divided into three age groups (early, mid-, and late adolescence). They completed a battery of scales comprising: Internet Gaming Disorder Scale-Short Form, Bergen Social Media Addiction Scale, Barratt Impulsiveness Scale for Adolescents, and Symptom Checklist-90-R.

Results: LPAs revealed distinct profiles across early, mid- and late adolescence with regards to the psychopathological variables taken into account. Specifically, only two profiles were identified in the 14-15 year age group, whereas three profiles emerged in the 16-17 year age group.

Conclusion: This study highlighted that the profiles identified in each age group differed in terms of psychopathological risk (low, medium and high), showing instead similar (and nonclinical) scores in technology-based addictions and impulsivity. Results could be useful in designing prevention and intervention programs in youth showing similar patterns for technology-based addictions, but different levels of psychopathological symptoms.

Keywords: internet gaming disorder, gaming addiction, social media addiction, online addictions, impulsivity, psychopathology

\section{Introduction}

Over the past couple of decades, advancements in digital technologies have brought about positive applications in health, education, and global connectivity. However, for a small minority of individuals, the overuse of these technologies has been associated with negative consequences, ranging from subjective distress to psychopathological symptoms. ${ }^{1}$ Among the various theoretical models of technologybased addictions, ${ }^{2}$ Griffiths' symptom-centered model $^{3}$ has been widely applied to the conceptualization of many technology-based addictions including internet 
gaming disorder (IGD; included in Section III - Emerging Measures and Models - of the most recent fifth edition of the Diagnostic and Statistical Manual of Mental Disorders [DSM-5], ${ }^{4}$ and social media addiction (SMA)] (which has no status in the DSM-5).

Griffiths' (2005) model comprises six symptoms: salience refers to when an addictive activity dominates a person's thinking, feelings, and behavior; mood modification refers to when people engage in specific activities to help change their mood states; tolerance refers to the need to increase the amounts of engagement in the addictive behavior to achieve the former effects; withdrawal refers to the unpleasant feeling states occurring when individuals decrease or suddenly reduce their addictive activities; conflict refers to the intrapsychic and interpersonal problems arising as a consequence of addictive activities; and relapse refers to the unsuccessful efforts to stop engaging in the addictive behavior if the individual is trying to cease.

With regard to the risk factors related to IGD and SMA, previous studies have found relationships between these two technology-based addictions and comorbid disorders such as attention-deficit/hyperactivity disorder, obsessive-compulsive disorder, ${ }^{5}$ depressive symptoms, ${ }^{6-8}$ mood and anxiety symptoms. ${ }^{9,10}$ In addition to psychopathological symptoms, impulsivity has been found to be one of the most predictive personality factors of IGD and SMA, especially in adolescent and emerging adult populations. ${ }^{11-17}$

These studies have been based on variable-centered approaches providing specific information on the importance of each factor to the outcome variable but are imprecise when assuming the homogeneity of the sampled individuals. ${ }^{18}$ In light of these limitations, person-centered approaches are useful in examining "similarities and differences among individuals with respect to how variables relate to each other". ${ }^{19}$ The advantages of this approach is that they: (i) can assess whether distinct groups of individuals can be identified via their naturalistic groupings of factors; (ii) offer complex combinations among all possible factors at all possible levels of each factor; and (iii) are appropriate for clinical practice because decisions concerning assessment and treatments are often focused on the individual rather than on the variable or factor. ${ }^{20}$

Given the ambiguous associations between psychopathology and IGD and SMA, as well as the need to apply a research method able to pinpoint the heterogeneity of the technology-based addictions in adolescent populations, ${ }^{21,22}$ the present study used the person-centered approach of latent profile analysis (LPA) to identify groups of adolescents who had similar profiles for multiple dimensions of psychopathology and online addictions. As this statistical method defines unobserved subgroups based on observed indicators without specifying the number of profiles in advance, it is considered a more appropriate method to address research questions that are exploratory in nature and to understand the diversity and complexity in multiple risk factor exposures in adolescent psychopathology. ${ }^{23}$

The present study intended to identify profiles of adolescents characterized by unique patterns of psychopathological risks (somatization, obsessive-compulsive, interpersonal sensitivity, depression, anxiety, hostility, phobic anxiety, paranoid ideation, psychoticism), impulsivity, and two technology-based addictions (ie, IGD and SMA). Gender was also included as suggested by previous literature. ${ }^{24,25}$ Given that no previous studies have reported a specific number of profiles, at least two classes were expected, one with low levels on all risk indictors and the other with high levels on all risk indicators. This study adds to previous literature in this field in that it focused on early-, mid- and late-adolescents. To our best knowledge, no study has done so; rather, other authors have concentrated on youths and emerging adults, prevalently assessing those samples as homogeneous groups. ${ }^{11}$

\section{Method}

\section{Participants and procedure}

A sample of 643 participants ( 312 males; $M_{\text {age }}=16.02$ years, $\mathrm{SD}=1.43$ ), was recruited from high schools in the regions of Central Italy through a convenience sampling, and divided into three age groups: early adolescence (14-15 years; $\mathrm{n}=259,40.3 \%$ of the entire sample), mid-adolescence (1617 years; $n=252,39.2 \%$ of the entire sample), and late adolescence (18-19 years; $n=132,20.5 \%$ of the entire sample). Participants were invited to complete an online self-report questionnaire which took approximately $50 \mathrm{mins}$ to complete. Data collection took place during March to May 2017 (data are available upon request to the authors at: http://dx.doi.org/10. 17632/n8ksj69mtt.2).

\section{Measures}

The Internet Gaming Disorder Scale-Short Form (IGDS9$\mathrm{SF}^{26}{ }^{26}$ Italian translation and validation ${ }^{27}$ ) is a nine-item, single-factor instrument based on DSM-5 IGD core 
criteria. It was devised to assess the severity and concomitant detrimental effects of IGD by examining both online and/or offline gaming activities over a 12-month period. The items are answered on a 5-point Likert scale ranging from 1 (Never) to 5 (Very often). Examples of items are: "Do you feel the need to spend increasing amount of time engaged gaming in order to achieve satisfaction or pleasure?" and "Have you continued your gaming activity despite knowing it was causing problems between you and other people?". Higher scores indicate a higher degree of gaming disorder. In the present study, the instrument exhibited very good reliability (Cronbach's $\alpha=0.88$ ).

The Bergen Social Media Addiction Scale (BSMAS; ${ }^{5}$ Italian translation and validation ${ }^{27}$ ) evaluates experiences in the use of social media within a 12-month period. It comprises six items rated on a 5-point Likert scale (from $1=$ Very rarely to $5=$ Very often) and related to core addiction elements, ie, salience, mood modification, tolerance, withdrawal, conflict, and relapse. Examples of items include: "How often during the last year have you used social media so much that it has had a negative impact on your job/studies?" and "How often during the last year have you felt an urge to use social media more and more?". In the present study, the internal consistency of the scale was good (Cronbach's $\alpha=0.78$ ).

The Barratt Impulsiveness Scale for Adolescents (BIS$11-\mathrm{A}^{.28,29}$ Italian translation and validation ${ }^{30}$ ) is the most widely used 30-item self-report instrument assessing the trait of impulsiveness. Each item is rated on a 4-point Likert scale (from $1=$ Never to $4=$ Very often). Representative items include: " $I$ do things without thinking" and "I say things without thinking". A total score is calculated with higher scores indicating higher levels of impulsiveness. In the present study, the overall impulsiveness score was calculated following Fossati et al.'s suggestions. $^{30}$ The internal consistency of the scale was good (Cronbach's $\alpha=0.78$ ).

The Symptom Checklist-90-R (SCL-90-R31 Italian translation and validation ${ }^{32}$ ) is a 90 -item self-report inventory that assesses the extent to which respondents have experienced the nine primary symptoms of psychopathology in the past seven days, namely, Somatization (SOM), Obsessive-Compulsive (O-C), Interpersonal Sensitivity (I-S), Depression (DEP), Anxiety (ANX), Hostility (HOS), Phobic Anxiety (PHOB), Paranoid Ideation (PAR), and Psychoticism (PSY). Each item is rated on a 5-point scale (from $1=$ No problem to $5=$ Very serious). In the present study, the subscales of the SCL90-R showed good to excellent internal consistencies (Cronbach's $\alpha=0.93$ for Somatization, 0.92 for Obsessive-Compulsive, 0.81 for Interpersonal Sensitivity, 0.89 for Depression, 0.90 for Anxiety, 0.74 for Hostility, 0.85 for Phobic Anxiety, 0.88 for Paranoid Ideation, and 0.89 for Psychoticism).

\section{Statistical analysis}

Data analyses included descriptive statistics (means and standard deviations) and Latent Profile Analyses (LPAs) for each age group to identify classes of adolescents with similar patterns across the individual risk factors (ie, gender, IGD, SMA, impulsiveness and the nine dimensions of psychopathology). The number of latent profiles was determined using three methods: (i) information-theoretic method, (ii) likelihood ratio statistical test method, and (iii) entropy-based criterion. The first method comprised the Akaike Information Criteria (AIC), the Bayesian Information Criteria (BIC), and the Sample-Size Adjusted BIC (SSA-BIC) with lower values indicating more parsimonious models. The second method comprised the Lo-Mendell-Rubin Adjusted Likelihood Ratio Test (LMRT) with a significant $p$-value $(<0.05)$. The final method comprised last criterion entropy values ranging from 0 to 1 with higher values indicating a better differentiation between profiles. ${ }^{33}$ Analyses were conducted using Mplus $8 .^{34}$

\section{Ethics}

The research study complied with the general ethical principles of the Declaration of Helsinki and was approved by the Institutional Review Board of International Telematic University Uninettuno (n.8/7/17). Permission was required from school heads to conduct the research. Written informed consent was obtained from students aged over 18 years and from parents or legal guardians for students aged under 18 years.

\section{Results}

Means and standard deviations of the study variables are shown in Table 1. This sample does not exceed the clinical cut-offs indicated in previous literature in any of the considered variables (for norms and cut-off points, please $\left.\operatorname{see}^{26,27,30,31}\right)$.

On the basis of the aforementioned individual risk factors, a series of latent profile models including two-tofour classes were estimated for the three age groups. The fit indices for each LPA are shown in Table 2. 
Table I Descriptive statistics for the variables of interest (total sample and each age group)

\begin{tabular}{|c|c|c|c|c|}
\hline & Total sample $(n=643)$ & $14-15$ years $(n=259)$ & $16-17$ years $(n=252)$ & $18-19$ years $(n=132)$ \\
\hline \multicolumn{5}{|l|}{ Mean (SD) } \\
\hline IGD & $1.62(0.748)$ & $1.66(0.763)$ & $1.63(0.757)$ & $1.54(0.699)$ \\
\hline SMA & $2.12(0.840)$ & $2.15(0.856)$ & $2.15(0.865)$ & $2.02(0.756)$ \\
\hline Impulsiveness & $2.59(0.39 I)$ & $2.58(0.394)$ & $2.60(0.395)$ & $2.59(0.382)$ \\
\hline \multicolumn{5}{|c|}{ Symptoms of psychopathology } \\
\hline SOM & $0.50(0.7 \mathrm{I})$ & $0.49(0.7 I)$ & $0.51(0.68)$ & $0.52(0.76)$ \\
\hline $\mathrm{O}-\mathrm{C}$ & $0.43(0.67)$ & $0.43(0.68)$ & $0.42(0.64)$ & $0.46(0.7 I)$ \\
\hline I-S & $0.44(0.55)$ & $0.43(0.54)$ & $0.44(0.53)$ & $0.45(0.59)$ \\
\hline DEP & $0.56(0.70)$ & $0.52(0.68)$ & $0.58(0.67)$ & $0.61(0.79)$ \\
\hline ANX & $0.46(0.66)$ & $0.45(0.67)$ & $0.45(0.63)$ & $0.51(0.72)$ \\
\hline HOS & $0.35(0.52)$ & $0.33(0.5 \mathrm{I})$ & $0.35(0.50)$ & $0.38(0.57)$ \\
\hline $\mathrm{PHOB}$ & $0.41(0.62)$ & $0.4 \mathrm{I}(0.62)$ & $0.40(0.59)$ & $0.43(0.66)$ \\
\hline PAR & $0.39(0.61)$ & $0.36(0.59)$ & $0.42(0.62)$ & $0.4 I(0.65)$ \\
\hline PSY & $0.45(0.63)$ & $0.44(0.62)$ & $0.44(0.59)$ & $0.48(0.70)$ \\
\hline
\end{tabular}

Abbreviations: IGD, internet gaming disorder; SMA, social media addiction; SOM, somatization; O-C, obsessive-compulsive; I-S, interpersonal sensitivity; DEP, depression; ANX, anxiety; HOS, hostility; PHOB, phobic anxiety; PAR, paranoid ideation; PSY, psychoticism.

Table 2 Fit statistics for latent profile analysis

\begin{tabular}{|c|c|c|c|c|c|}
\hline & AIC & BIC & SSA-BIC & Entropy & LMRT ( $p$-value) \\
\hline \multicolumn{6}{|c|}{ Age group $14-15$ years } \\
\hline 2 Classes & 3403.167 & 3541.884 & 3418.24 & $\mathbf{I}$ & $\begin{array}{l}2885.58 \\
p=0.007\end{array}$ \\
\hline 3 Classes & 2197.516 & 2386.028 & 2217.999 & 0.999 & $\begin{array}{l}1217.995 \\
p=0.020\end{array}$ \\
\hline 4 Classes & $187 \mid .76$ & 2110.067 & 1897.653 & 0.998 & $\begin{array}{l}349.267 \\
p=0.210\end{array}$ \\
\hline \multicolumn{6}{|c|}{ Age group $16-17$ years } \\
\hline 2 Classes & 3596.87 & 3734.52 & 3610.88 & 0.999 & $\begin{array}{l}2381.99 \\
p=0.009\end{array}$ \\
\hline 3 Classes & 2289.648 & 2476.708 & 2308.69 & 0.999 & $\begin{array}{l}1318.197 \\
p=0.001\end{array}$ \\
\hline 4 Classes & 1851.704 & 2088.176 & 1875.776 & 0.998 & $\begin{array}{l}460.002 \\
p=0.127\end{array}$ \\
\hline \multicolumn{6}{|c|}{ Age group $18-19$ years } \\
\hline 2 Classes & 1912.36 & 2024.79 & 1901.43 & I & $\begin{array}{l}1472.135 \\
p=0.060\end{array}$ \\
\hline
\end{tabular}

Note: Boldface indicates the selected model.

Abbreviations: AIC, Akaike Information Criterion; BIC, Bayesian Information Criterion; SSA-BIC, Sample-Size Adjusted BIC; LMRT, Lo-Mendell-Rubin Test.

Although the values of AIC, BIC and SSA-BIC were lower for the three- and four-class solutions, the two-class model was retained for $14-15$ year age group due to the significant LMRT value $(p=0.007)$ and the highest Entropy value. Class 1 comprised 212 participants $(81.85 \%$ of the group) characterized by low levels of psychopathological symptoms and higher (non-clinical) levels of IGD, SMA, and impulsiveness, whereas Class 2 comprised 47 participants (15.15\% of the group) with higher (non-clinical) levels of IGD, SMA, impulsiveness and psychopathological 
symptoms. Both classes reported extremely high levels of impulsiveness, followed by high levels of SMA, and moderate levels of IGD. Although scores of psychopathological symptoms in Class 2 were not clinical, Depression and Anxiety levels were higher than other scores in youths aged 14-15 (Figure 1).

With regard to gender, the probability that an individual in the first class was female was 0.47 and in the second class 0.60 . In short, females were less likely to be in Class 1 than males, but more likely to be in Class 2 than males. As for the age groups 16-17 years and 18-19 years, the LMRT $(p<0.05)$ and Entropy values indicated that the three-class solution fitted better than the two- and fourclass models. More specifically, in the 16-17 year age group, the lower AIC, BIC, and SSA-BIC values, together with a lower significant value of LMRT, favored a threeclass solution. Class $1(78.96 \%$ of the group, $n=199)$ comprised individuals with low levels of psychopathological symptoms and higher (non-clinical) levels of impulsiveness, SMA, and IGD; Class 2 (14.28\% of the group, $\mathrm{n}=36$ ) comprised individuals characterized by moderate (non-clinical) levels of psychopathological symptoms, with higher (non-clinical) scores in depression, impulsiveness, SMA, and IGD; Class 3 (6.75\% of the group, $n=17)$ comprised individuals with high psychopathological symptoms, especially somatization, anxiety, phobic anxiety, and psychoticism, and lower levels of impulsivity, SMA and IGD in comparison to Classes 1 and 2. As for class 1 and 2, these subjects did not exceed clinical cut- offs for any of the considered variables. Although psychopathological symptoms in youths aged 16-17 did not reach clinical significance, it must be noted that in Class 2 midadolescents scored higher on Depression, whereas in Class 3 (where all scores were higher than Class 2), they showed highest scores on Somatization, Anxiety, Hostility and Psychoticism (Figure 2).

As for gender, the probability that an individual in Class 1 was female was 0.54, in e 2 was 0.50 , and in Class 3 was 0.29. In short, females were more likely to be in Class 1 than males, but less likely to be in Class 3 than males. However, males and females had the same probability of being in Class 2 .

When looking at the final age group (18-19 years), the LMRT $p$-value was not significant for the two-class solution, indicating that this class solution did not fit the data better than a one-class solution and, consequently, there were no relevant classes in this subgroup.

Indicator means for each class in each age group are shown in Table 3.

\section{Discussion}

The present study sought to define adolescent profiles characterized by different patterns of psychopathological risks, impulsivity, and two specific technology-based addictions - internet gaming disorder (IGD) and social media addiction (SMA). Overall, results from the Latent Profile Analysis (LPA) provided a nuanced understanding of the relative contribution of each factor to risk exposure across age. For this purpose, the total sample was divided

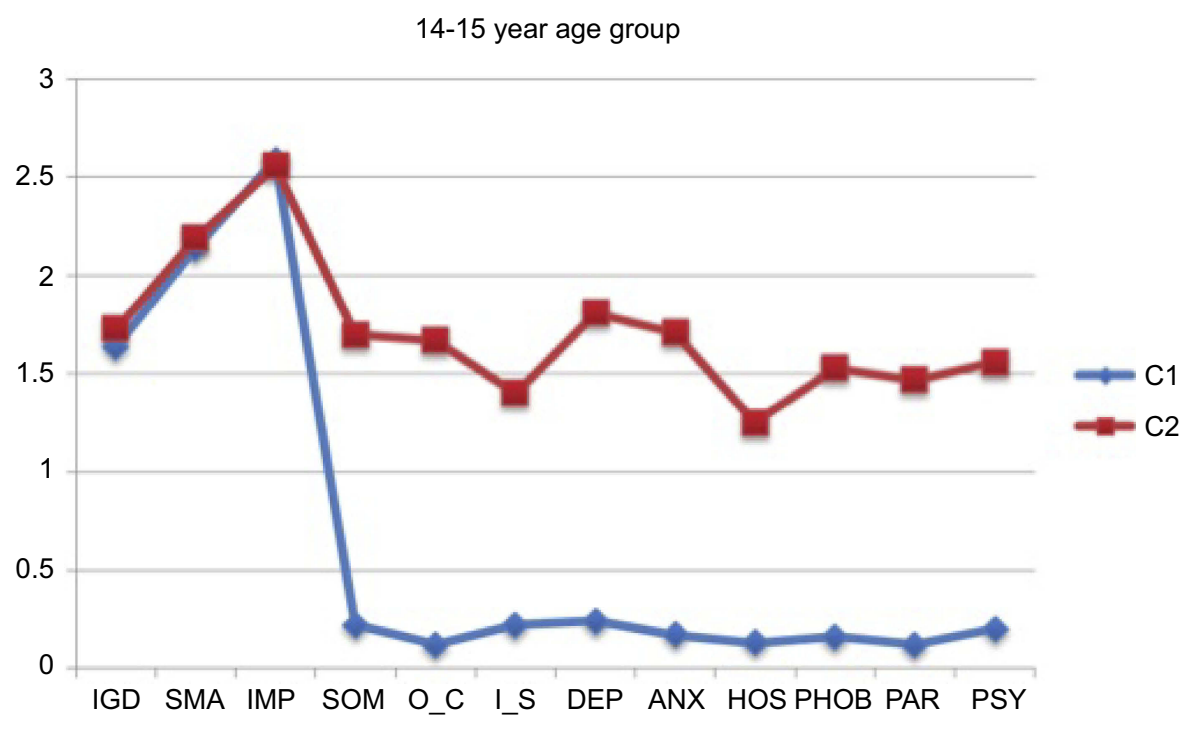

Figure I Latent profile analysis (LPA) for 14-15 year age group.

Abbreviations: IGD, internet gaming disorder; SMA, social media addiction; IMP, impulsivity; SOM, somatization; O-C, obsessive-compulsive; I-S, interpersonal sensitivity; DEP, depression; ANX, anxiety; HOS, hostility; PHOB, phobic anxiety; PAR, paranoid ideation; PSY, psychoticism. 


\section{6-17 year age group}

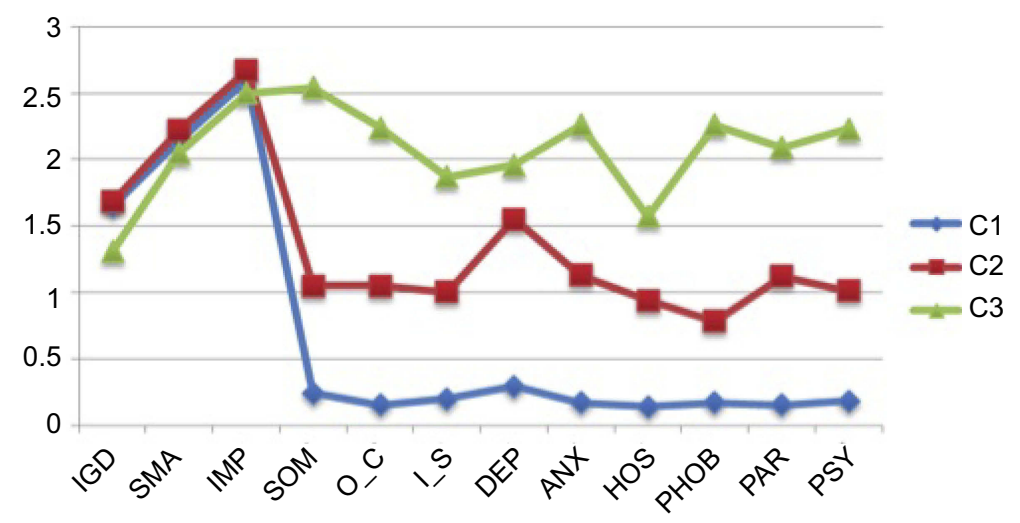

Figure 2 Latent profile analysis (LPA) for 14-15 year age group.

Abbreviations: IGD, internet gaming disorder; SMA, social media addiction; IMP, impulsivity; SOM, somatization; O-C, obsessive-compulsive; I-S, interpersonal sensitivity; DEP, depression; ANX, anxiety; HOS, hostility; PHOB, phobic anxiety; PAR, paranoid ideation; PSY, psychoticism.

into three age groups: early, mid and late adolescence, following Steinberg's suggestions. ${ }^{35}$

Findings from the LPAs demonstrated that there are no relevant differences between groups as regards IGD, SMA and impulsiveness, but there are groups with low, medium and high (yet non-clinical) patterns of psychopathological symptoms, independently of their level of IGD, SMA and impulsiveness. More specifically, only two profiles were identified in the 14-15 year age group, whereas three profiles emerged in the other two age groups. The two profiles of early adolescents were similar to technology-based addictions and impulsivity, but distinct in psychopathological risks. Although scores of psychopathological symptoms in Class 2 were not clinical, Depression and Anxiety levels were higher than other scores in youths aged 14-15. We can speculate that adolescents in the first profile might use videogames and social media to increase levels of emotional activation, while youths in the second profile might use technologies wanting to reduce the psychological discomfort. ${ }^{36-39}$

In mid-adolescence (16-17 years), the three profiles identified were similar in psychopathological risks, but different in technology-based addictions and impulsivity. Indeed, mid-aged adolescents in the third profile were characterized by higher levels of psychopathological risks associated with higher levels of SMA, but lower levels of IGD. Although psychopathological symptoms in youths aged 16-17 did not reach clinical significance, it must be noted that in Class 3 (where all scores were higher than Class 2), they showed highest scores on Somatization, Anxiety, Hostility and Psychoticism. Differently from younger adolescents, these youths show a more complex psychological functioning.
In brief, LPAs showed that no different groups exist in this sample with regards to levels of IGD and SMA, but different classes emerge both in 14-15 and 16-17 youths with regards to psychopathological risk. This was an unexpected result considering previous literature, which suggested correlations between these variables. Nonetheless, a seminal work found strongest associations in the adult population, rather than in adolescents, probably because older subjects experienced the negative consequences of the technology misuse for a longer period, and this has eventually led to comorbid psychopathology. ${ }^{11}$

With regard to gender, the LPAs showed that in all age groups, females were more likely to belong to less problematic profiles (namely, Class 1) than males, except for their levels of impulsivity. However, it is noteworthy that the levels of IGD and SMA were similar between the profiles in all age groups but the profiles were differentiated principally with respect to the levels of psychopathological symptoms. Here, although boys and girls showed similar scores in IGD and SMA, they belonged to different profiles given the causal relationship that could associate problematic use of social networking and gaming with psychopathology (which was unexplored in this cross-sectional study). For example, problematic gaming and excessive use of social networking sites in males might lead to an increase of psychopathological symptoms, whereas in girls they might reduce the symptoms on the basis of the differences between boys and girls in choosing the type of videogame and social networking site (for males: playing games, shooter games, and Facebook; for females: adventure games, quiz games, and Instagram) $)^{40,41}$ and in the motivations driving them (for males: competition; for females: emotional closeness). ${ }^{42}$ 


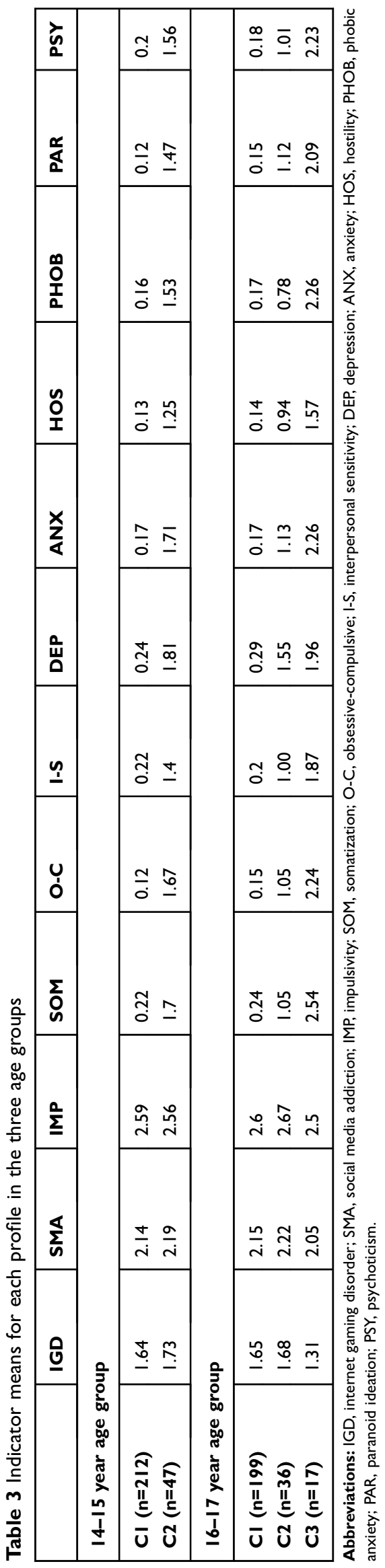

The results of the present study should be interpreted in light of some limitations. First, the homogeneity of the sample in terms of race and geographical origin does not enable broad generalization of the results to a wider population. Second, although the psychometric tools used in this research were valid and reliable, they were self-report measures and are open to well-known biases (such as those associated with social desirability and memory recall). Third, the cross-sectional nature of the present research limited the possibility to draw meaningful conclusions about the cause-and-effect relationship between the variables examined.

\section{Acknowledgments}

This research did not receive any specific grant from funding agencies in the public, commercial, or not-for-profit sectors.

\section{Author contributions}

All authors contributed toward data analysis, drafting and revising the paper, gave final approval of the version to be published and agree to be accountable for all aspects of the work.

\section{Disclosure}

The authors declare no conflicts of interest in this work.

\section{References}

1. Kuss DJ, Billieux J. Technological addictions: conceptualisation, measurement, etiology and treatment. Addict Behav. 2017;64:231-233. doi:10.1016/j.addbeh.2016.04.005

2. King DL, Haagsma MC, Delfabbro PH, Gradisar M, Griffiths MD. Toward a consensus definition of pathological video-gaming: a systematic review of psychometric assessment tools. Clin Psychol Rev. 2013;33(3):331-342. doi:10.1016/j.cpr.2013.01.002

3. Griffiths MD. A 'components' model of addiction within a biopsychosocial framework. J Subst Use. 2005;10:191-197. doi:10.1080/ 14659890500114359

4. American Psychiatric Association (APA). Diagnostic and Statistical Manual of Mental Disorders. 5th.; DSM-5. Washington, DC: American Psychiatric Association; 2013.

5. Andreassen CS, Billieux J, Griffiths MD, et al. The relationship between addictive use of social media and video games and symptoms of psychiatric disorders: a large-scale cross-sectional study. Psychol Addict Behav. 2016;30(2):252-262. doi:10.1037/adb0000160

6. Lin LY, Sidani JE, Shensa A, et al. Association between social media use and depression among U.S. young adults. Depress Anxiety. 2016;33(4):323-331. doi:10.1002/da.22466

7. Shensa A, Escobar-Viera CG, Sidani JE, Bowman ND, Marshal MP, Primack BA. Problematic social media use and depressive symptoms among U.S. young adults: a nationally-representative study. Soc Sci Med. 1982;182:150-157. doi:10.1016/j.socscimed.2017.03.061

8. Kim NR, Hwang SSH, Choi JS, et al. Characteristics and psychiatric symptoms of internet gaming disorder among adults using selfreported DSM-5 criteria. Psychiatry Investig. 2016;13(1):58-66. doi:10.4306/pi.2016.13.1.58 
9. Mansueto G, Pennelli M, De Palo V, Monacis L, Sinatra M, De Caro MF. The role of metacognition in pathological gambling: a mediation model. J Gambl Stud. 2016;32(1):93-106. doi:10.1007/s10899-0149519-5

10. Pontes H. Investigating the differential effects of social networking site addiction and Internet gaming disorder on psychological health. Addict Behav Addict. 2017;6(4):601-610. doi:10.1556/2006.6. 2017.075

11. González-Bueso V, Santamaría J, Fernández D, Merino L, Montero E, Ribas J. Association between internet gaming disorder or pathological video-game use and comorbid psychopathology: a comprehensive review. Int J Environ Res Public Health. 2018;15(4):668. doi:10.3390/ijerph15061188

12. Cerniglia L, Zoratto F, Cimino S, Laviola G, Ammaniti M, Adriani W. Internet addiction in adolescence: neurobiological, psychosocial and clinical issues. Neurosci Biobehav Rev. 2017;76:174-184. doi:10.1016/j.neubiorev.2016.12.024

13. Hu J, Zhen S, Yu C, Zhang Q, Zhang W. Sensation seeking and online gaming addiction in adolescents: a moderated mediation model of positive affective associations and impulsivity. Front Psychol. 2017;8:699. doi:10.3389/fpsyg.2017.00699

14. Sinatra M, de Palo V, Contini P, Volpicella V. Identity styles and internet-related addictive behaviors in adolescents. Turk Online J Educ Technol. 2016;15:1161-1165.

15. Paulus FW, Ohmann S, Von Gontard A, Popow C. Internet gaming disorder in children and adolescents: a systematic review. Dev Med Child Neurol. 2018;60(7):645-659. doi:10.1111/dmcn.13754

16. Alsehaima AO, Alanazi AA. Psychological and social risks to children of using the internet: literature review. J Child Adolesc Behav. 2018;6(380):2. doi:10.4172/2375-4494.1000380

17. Durkee T, Carli V, Floderus B, et al. Pathological internet use and risk-behaviors among European adolescents. Int J Environ Res Public Health. 2016;13(3):294. doi:10.3390/ijerph13121252

18. Li D, Li X, Zhao L, Zhou Y, Sun W, Wang Y. Linking multiple risk exposure profiles with adolescent internet addiction: insights from the person-centered approach. Comput Human Behav. 2017;75:236-244. doi:10.1016/j.chb.2017.04.063

19. Masyn KE. Latent class analysis and finite mixture modeling. In: Little TD, editor. Statistical Analysis (vol. 2). The Oxford Handbook of Quantitative Methods. New York: Oxford University Press; 2013:551-611.

20. Hallquist MN, Wright AG. Mixture modeling methods for the assessment of normal and abnormal personality, part I: cross-sectional models. J Pers Assess. 2013;96(3):256-268. doi:10.1080/ 00223891.2013 .845201

21. Moreau A, Laconi S, Delfour M, Chabrol H. Psychopathological profiles of adolescent and young adult problematic Facebook users. Comput Human Behav. 2015;44:64-69. doi:10.1016/j. chb.2014.11.045

22. Wartberg L, Kriston L, Kammerl R, Petersen KU, Thomasius R. Prevalence of pathological internet use in a representative German sample of adolescents: results of a latent profile analysis. Psychopathology. 2015;48(1):25-30. doi:10.1159/000365095

23. Pontes H, Griffiths MD. Measuring DSM-5 internet gaming disorder: development and validation of a short psychometric scale. Comput Human Behav. 2015;45:137-143. doi:10.1016/j. chb.2014.12.00

24. Reiner I, Tibubos AN, Hardt J, Müller K, Wölfling K, Beutel ME. Peer attachment, specific patterns of internet use and problematic internet use in male and female adolescents. Eur Child Adolesc Psychiatry. 2017;26(10):1257-1268. doi:10.1007/s00787-0170984-0
25. Sun Y, Wang Y, Han X, et al. Sex differences in resting-state cerebral activity alterations in internet gaming disorder. Brain Imaging Behav. Epub 2018 Sep 4

26. Monacis L, de Palo V, Griffiths MD, Sinatra M. Validation of the Internet Gaming Disorder Scale-Short Form (IGDS9-SF) in an Italian-speaking sample. Addict Behav Addict. 2016;5(4):683-690. doi:10.1556/2006.5.2016.083

27. Monacis L, de Palo V, Griffiths MD, Sinatra M. Social networking addiction, attachment style, and validation of the Italian version of the Bergen social media addiction scale. Addict Behav Addict. 2017;6:178-186. doi:10.1556/2006.6.2017.023

28. Barratt ES. Factor analysis of some psychometric measures of impulsiveness and anxiety. Psychol Rep. 1965;16(2):547-554. doi:10.2466/ pr0.1965.16.2.547

29. Patton JH, Stanford MS, Barratt ES. Factor structure of the Barratt Impulsiveness Scale. J Clin Psychol. 1995;51(6):768-774. doi:10.1002/1097-4679(199511)51:63.0.CO;2-1

30. Fossati A, Di Ceglie A, Acquarini E, Barratt ES. Psychometric properties of an Italian version of the Barratt Impulsiveness Scale11 (BIS-11) in nonclinical subjects. J Clin Psychol. 2001;57(6):815828. doi:10.2466/pms.2002.95.2.621

31. Derogatis LR. Symptom Checklist-90-Revised: Administration, Scoring and Procedures Manual. Minneapolis, MN: National Computer Systems; 1994.

32. Prunas A, Sarno I, Preti E, Madeddu F, Perugini M. Psychometric properties of the Italian version of the SCL-90-R: a study on a large community sample. Eur Psychiatry. 2012;27(8):591-597. doi:10.1016/j.eurpsy.2010.12.006

33. Nylund KL, Asparouhov T, Muthén BO. Deciding on the number of classes in latent class analysis and growth mixture modeling: a Monte Carlo simulation study. Struct Equ Modeling. 2007;14(4):535-569. doi:10.1080/10705510701575396

34. Muthén LK, Muthén BO. MPlus User's Guide. 8th ed. Los Angeles, CA: Muthen \& Muthen; 1998-2017.

35. Steinberg L. Adolescence. 6th ed. Boston, MA: McGraw Hill; 2002.

36. Cerniglia L, Cimino S, Ballarotto G, et al. Motor vehicle accidents and adolescents: an empirical study on their emotional and behavioral profiles, defense strategies and parental support. Transp Res Part F Traffic Psychol Behav. 2015;35(1):28-36. doi:10.1016/j.trf.2015.09.002

37. Cimino S, Cerniglia L. A longitudinal study for the empirical validation of an etiopathogenetic model of internet addiction in adolescence based on early emotion regulation. Biomed Res Int. 2018;4038541:18. doi:10.1155/2018/4038541

38. Cimino S, Cerniglia L, Porreca A, Simonelli A, Ronconi L, Ballarotto G. Mothers and fathers with binge eating disorder and their 18-36 months old children: a longitudinal study on parentinfant interactions and offspring's emotional-behavioral profiles. Front Psychol. 2016;7:580. doi:10.3389/fpsyg.2016.00580

39. Laconi S, Pires S, Chabrol H. Internet gaming disorder, motives, game genres and psychopathology. Comput Human Behav. 2017;75:652-659. doi:10.1016/j.chb.2017.06.012

40. Lenhart A, Duggan M, Perrin A, Stepler R, Rainie L, Parker K (2015). Teens, social media \& technology overview. Pew Research Center. Available from: http://www.pewinternet.org/files/2015/04/PI TeensandTech_Update2015_0409151.pdf. Accessed March 24, 2018

41. Rehbein F, Staudt A, Hanslmaier M, Kliem S. Video game playing in the general adult population of Germany: can higher gaming time of males be explained by gender specific genre preferences?. Comput Human Behav. 2016;55:729-735. doi:10.1016/j.chb.2015.10.016

42. Kuss DJ, Griffiths MD, Karila L, Billieux J. Internet addiction: a systematic review of epidemiological research for the last decade. Curr Pharm Des. 2014;20:4026-4052. doi:10.2174/13816128113199990617 


\section{Publish your work in this journal}

Psychology Research and Behavior Management is an international, peer-reviewed, open access journal focusing on the science of psychology and its application in behavior management to develop improved outcomes in the clinical, educational, sports and business arenas. Specific topics covered in the journal include: Neuroscience, memory and decision making; Behavior modification and management; Clinica

applications; Business and sports performance management; Social and developmental studies; Animal studies. The manuscript management system is completely online and includes a very quick and fair peer-review system, which is all easy to use. Visit http://www. dovepress.com/testimonials.php to read real quotes from published authors. 